Published in Information Literacy in Everyday Life. ECIL 2018. Communications in Computer and Information Science, vol 989. Eds by: Kurbanoğlu S. et al. Cham: Springer, 2019, pp. 443-453. ISBN:978-3-030-13472-3.

https://doi.org/10.1007/978-3-030-13472-3 42

\title{
How Does Information Literacy Instruction in Secondary Education Affect Students' Self-Efficacy Beliefs and Attitudes?
}

\author{
Tuulikki Alamettälä, Eero Sormunen, and Md Arman Hossain \\ University of Tampere, Faculty of Communication Sciences, Tampere, Finland \\ \{tuulikki.alamettala, eero.sormunen\}@uta.fi, \\ armanhossain.isl@gmail.com
}

\begin{abstract}
This paper reports the findings of a study on how students' self-efficacy in and attitudes to online research develop in a two-year information literacy intervention in the lower secondary school. The data was collected by a questionnaire administered before, in the middle of, and after the intervention. A repeated measures ANOVA was used to reveal the effect of the intervention. The teaching intervention changed students' behavioral intentions in the evaluation of search results and in source-based writing. No intervention effect was observed in other attitude factors or in self-efficacy beliefs. The authors suggest that selfefficacy and attitudes should be considered as explicit learning goals in pedagogical practices in order to develop them more effectively.
\end{abstract}

Keywords: Information literacy instruction, online research, intervention.

\section{Introduction}

Information literacy (IL) is defined as 'a set of abilities individuals require to recognise the information need and to locate, evaluate and use the needed information effectively' [1]. IL instruction typically aims to improve students' IL skills, and learning outcomes are assessed accordingly [2]. As argued by Pinto and Fernandez-Pascual [3], the concept of IL can be extended beyond knowledge and skills to include attitudes and motivations of individuals for searching, evaluating, processing, and communicating information. The aim of this study is to examine how long-term inquiry-based curriculum-embedded IL instruction affects students' self-efficacy beliefs and attitudes.

Bandura [4] defined self-efficacy as individuals' confidence in their own capabilities to organize and execute the course of actions required to perform a task or attain a goal. Previous research suggests that individuals with high self-efficacy use their skills [5] and develop their skills [6]. Individuals with low self-efficacy tend to avoid challenging activities [7] and are less likely to develop their competencies [8]. Aesaert et al. [6] found that competent primary school students had quite realistic ICT-related selfefficacy beliefs, but less competent students overestimated their ability severely. The researchers suggested that realistic but slightly overoptimistic beliefs have a positive effect on students' acquisition of competences.

Eagly and Chaiken [9] defined attitude as 'a psychological tendency that is 
expressed by evaluating a particular entity with some degree of favour or disfavour'.

We adopt here the three-component model of attitudes widely used in social psychology to define the construct of attitudes [10]. The three components are 1) affect (feelings, likes, or dislikes about the attitude object), 2) cognition (ideas and beliefs about the attitude object), and 3) behavioral intention (the intention to act a certain way with regard to the attitude object).

Our literature review did not reveal any previous studies on how IL instruction changes students' self-efficacy beliefs and attitudes in primary or lower secondary schools. Pinto and Fernandez-Pascual [11] conducted a study having the same elements but university students as subjects. They carried out an intervention study on the firstyear library and information science students and measured students' attitudes and selfefficacy before and after the intervention. Students' self-efficacy increased in relation to 23 IL skills, but attitudes improved only in nine skills.

Some studies in science education suggest that guided-inquiry approaches have positive effects on both the young students' cognitive and affective characteristics. For example, Gibson and Chase [12] found that learners' attitudes toward science can be improved through teaching interventions. Koksal and Berberoglu [13] found that a guided-inquiry teaching intervention improved sixth graders' attitude toward science.

Our literature review indicates that we lack studies on how IL instruction affects students' self-efficacy beliefs and attitudes in primary or lower secondary schools. However, studies in other fields, such as ICT education, indicate that self-efficacy beliefs and attitudes may influence how students acquire new competences and skills. Hence we should understand better how the various ways of teaching IL and online research affect these traits. Another poorly studied area is how teaching affects students' conceptions of good practices in online research.

We argue that although it is important that instruction develops students' skills, there are other factors, such as attitudes and self-efficacy beliefs, which should also be considered as learning goals. Attitudes and self-efficacy beliefs have a role in how students engage with the task at hand and use their skills. A wide range of research in psychology gives evidence that attitudes affect individuals' behavior [14-15]. The same mechanism can be concluded to hold for information practices, see [16]. Enhanced selfefficacy beliefs in and attitudes to online research provide the potential to encourage students to actively practice and exploit their IL skills.

The study focuses on the following research questions:

1. How does the teaching intervention change students' self-efficacy beliefs in online research?

2. How does the teaching intervention change students' attitudes to online research?

\section{$2 \quad$ Methods}

The nature of this study was quasi-experimental using a non-equivalent groups design. The selection of groups was based on a convenience sample. Quasi-experiments are 
useful in cases where the random assignment of subjects into test and control groups is difficult, for example, in intervention studies conducted in schools [17-18].

\subsection{Participants and procedure}

The study was conducted in a lower secondary school located in a medium-sized city in southern Finland. The total number of students in the school is about 300, and they all are from the neighbouring area. All students have access to the school without entrance examinations. The school serves as a teacher training school.

Data collection was started in the autumn term 2015 when the students entered seventh grade (13-14 years old) and was completed in the spring term 2017 when the students completed their eighth grade (14-15 years old). The intervention group consisted of three parallel classes ( 35 girls and 23 boys). Two other classes not exposed to the intervention performed as a control group (19 girls and 17 boys). Thus, the number of students was 58 in the intervention group and 36 in the control group.

The intervention was integrated into three courses held in autumn term 2015 (Course 1), spring term 2016 (Course 2), and autumn term 2016 (Course 3). The intervention was designed and implemented by a Finnish language teacher. The second course combined Finnish language and history, and two history teachers collaborated to organize it. All teachers had years of experience and were also training student teachers. The control group was taught by teachers working independently from the intervention.

The courses were within the regular curriculum of the school, but the teachers redesigned them to emphasize information literacy skills as an important learning goal. In the beginning, Guided Inquiry [19] was introduced to the teachers, but they were free to embed it into their pedagogical practices as extensively as they thought appropriate. The key instructional principles of Guided Inquiry that the teachers aimed to follow were: to devote attention to the first phases of the inquiry process and to give more space for students to choose topics that interested them. In order to keep track of information sources, inquiry logs were introduced to the students.

In course 1, students made a brochure about good practices in social media. In course 2 , students worked on a source-based presentation and a fictional text, both about the Finnish Civil War. In course 3, each student prepared and presented an argumentative speech. The main learning goals were that the students learn to search information on the Web, evaluate sources critically, and use information meaningfully in a given task. The details of the teaching intervention are reported in [20]. The control group received standard instruction based on the curriculum.

\subsection{Materials}

The survey tool to measure self-reported attitudes and self-efficacy beliefs was designed by using the validated SORAB (Survey of Online Reading Attitudes and Behaviours) instrument by Putman [21] as a framework. Because the SORAB survey is designed only for online research, we added a set of items to cover library aspects of information 
searching and use.

To develop a survey of self-efficacy beliefs, we first modelled the online research process into three subtasks: 'Web searching', 'evaluation of sources', and 'use of Web sources' and designed new candidate items for each subtask. A set of items was adopted from the SORAB's Efficacy for Online Reading factor, and included in the subtask model. Further, three items of library use were added. The resulting scale included one generic item for online research, five for Web searching, four for the use of the library, six for evaluation, and six for writing. All items started with the phrase 'I am able to ...'. A 5-point Likert scale from 'Very well' to 'Not at all' was used.

A set of items for the attitude components affect and cognition were adopted from the SORAB's factors F3 (Anxiety) and F5 (Value/Interest). The core set was extended by items about traditional learning materials and their use. Eight items were related to positive and four items to negative attitudes toward online research. Four items contrasted Web and printed sources, six related to traditional forms of learning and use of learning materials, and two dealt with use of the library - 24 items in total. A 5-point Likert scale from 'Fully agree' to 'Fully disagree' was also used here.

The third attitude component was designed to measure behavioural intentions in online research. It was based on a careful analysis of good practices for analysing information needs, formulating search statements, evaluating and reading search results, and writing texts based on selected sources. Ten items were related to the planning and searching stage, fifteen to the reading, evaluation, and selection stage, and eight to the use of sources in writing the end-product (33 items in total). A 5-point Likert scale ranged from 'I always do this way' to 'I never do this way'.

\subsection{Data Collection}

The questionnaire was administered before the intervention, after the second course, and after the intervention. The items on self-efficacy beliefs and attitudes regarding behavioural intentions were included in all three data collections. The affect and cognition components of attitudes were surveyed only two times (pre and post) to avoid students' overloading.

The total number of students participating in the survey was 94 . Two outliers, whose answers showed that they had filled in the questionnaires without consideration, dropped the number of students to 92 . Some students were absent in one of the data collections or failed to answer some individual items. Because SPSS applied listwise deletion of subjects in case of missing data, the number of students in the statistical analysis varied from 78 to 82 .

The first step was to conduct an exploratory factor analysis (EFA) to find reliable scales for the measurement of students' self-efficacy beliefs and attitudes. The number of students in the study was quite small compared to the number of items [see 22, $p$. 683-685]. The problem was solved by grouping the items into five theoretically consistent subsets and applying EFA to these subsets. 
Table 1. The summary of the factor analysis and reliability tests

\begin{tabular}{|l|c|c|c|c|l|}
\hline Factors & $\begin{array}{l}\text { Number } \\
\text { of items }\end{array}$ & Loadings & $\begin{array}{l}\text { Cronbach's } \\
\text { alpha }\end{array}$ & $\begin{array}{c}\text { Test-retest } \\
\text { reliability } *)\end{array}$ & $\begin{array}{l}\text { Examples of representative } \\
\text { items (translated) }\end{array}$ \\
\hline $\begin{array}{l}\text { Attitudes: } \\
\text { Searching } \\
\text { intentions }\end{array}$ & 7 & - & .779 & $.506-.661$ & $\begin{array}{l}\text { Before a search, I think } \\
\text { carefully which keywords I } \\
\text { will use. }\end{array}$ \\
\hline $\begin{array}{l}\text { Attitudes: } \\
\text { Evaluation } \\
\text { intentions }\end{array}$ & 5 & - & .785 & $.500-.581$ & $\begin{array}{l}\text { I try to find out who is the } \\
\text { author of the webpage. }\end{array}$ \\
\hline $\begin{array}{l}\text { Attitudes: } \\
\text { Writing } \\
\text { intentions }\end{array}$ & 4 & - & .736 & $.560-.680$ & $\begin{array}{l}\text { I prepare myself for writing } \\
\text { by taking notes from } \\
\text { sources. }\end{array}$ \\
\hline $\begin{array}{l}\text { Attitudes: } \\
\text { Online } \\
\text { Learning }\end{array}$ & 4 & $.645-.803$ & .774 & $\begin{array}{l}\text { It is important for me to be } \\
\text { good at searching } \\
\text { information on the Web. }\end{array}$ \\
\hline $\begin{array}{l}\text { Attitudes: } \\
\text { Traditional } \\
\text { Learning }\end{array}$ & 4 & $.572-.730$ & .739 & $\begin{array}{l}\text { I like to search information } \\
\text { in the library (books, } \\
\text { journals). }\end{array}$ \\
\hline $\begin{array}{l}\text { Self-efficacy: } \\
\text { Searching }\end{array}$ & 3 & $.622-.825$ & .746 & $.424-.525$ & $\begin{array}{l}\text { I am able to choose the best } \\
\text { link from the search } \\
\text { engine's result page. }\end{array}$ \\
\hline $\begin{array}{l}\text { Self-efficacy: } \\
\text { Writing }\end{array}$ & 3 & $.620-.748$ & .727 & $.504-.570$ & $\begin{array}{l}\text { I am able to make notes of } \\
\text { what I have read. }\end{array}$ \\
\hline
\end{tabular}

*) all statistically significant $p<0.01$

Data distributions for ten items deviated seriously from normality (|kurtosis| or $\mid$ skewness $\mid>1$ ) and were removed before EFA. Principal axis factoring was used as the extraction method with oblique rotation (Direct oblimin) with requirements: communalities $>0.3$, loadings $>0.4$, cross-loadings $<0.3$, and Kaiser-Meyer-Olkin measure $(\mathrm{KMO})>0.5$. Eigenvalues $(>1)$ and scree plots were analyzed to find a good estimate for the number of factors searched [see 22, p.665-706]. The EFA results are summarized in Table 1.

The reliability of psychometric scales are typically estimated by Cronbach's alpha. All scales meet the requirement for $\alpha>0.7$ [see 22, p.709]. In addition, we could estimate the test-retest reliability by analysing correlations (Pearson's $r$ ) of data collected by the same scale three times (only two for the attitude components affect and cognition). All correlations were statistically significant $(\mathrm{p}<0.01)$ and mostly higher than .5. Although scores as high as .8 are desirable, in practice such high scores are difficult to achieve in scales for behaviour, beliefs, and attitudes [23]. We argue that we had enough evidence of the stability of our scales to be used in this study.

\subsection{Statistical Analysis}

Statistical analyses were performed using SPSS version 25 . Normality checks were carried out numerically by the Shapiro-Wilk Test because our data set is relatively small. The sets of data which did not pass the Shapiro-Wilk Test were evaluated graphically using the normal Q-Q Plots. All data was at least approximately normally distributed.

A mixed between-within subjects ANOVA was conducted to assess the impact of 
the teaching intervention. A mixed between-within subjects ANOVA is an extension of a repeated measures ANOVA and can be used in a study with two independent variables: one is a between-subjects variable (e.g., group: intervention/control) and the other a within-subjects variable (e.g. time: pre/post). [24, p.284-292.]

\section{$3 \quad$ Results}

The key results are presented in Table 2. The results suggest that the students in the intervention group adopted more positive behavioural intentions in the evaluation of search results $\left(\mathrm{F}(2,154)=4.05, \mathrm{p}=.019\right.$, partial $\left.\eta^{2}=.050\right)$. The effect size was nearly medium (suggested norms for partial eta-squared: small $=.01$; medium $=.06$; large $=$ $.14[24$, p.217-218]). Within-subjects contrasts revealed that the differences were statistically significant between pre- and post-measurements $\left(p=.004\right.$, partial $\eta^{2}=$ $.103)$, and between pre- and mid-measurements $\left(p=.048\right.$, partial $\left.\eta^{2}=.050\right)$. No learning effect was observed after the midpoint $(\mathrm{p}=.575)$.

Table 2. The scores of attitudes and self-efficacy beliefs measured before (PRE), in the middle of (MID), and after (POST) the intervention.

\begin{tabular}{|c|c|c|c|c|c|c|c|c|c|c|c|}
\hline \multirow{2}{*}{ ITEM } & \multirow[b]{2}{*}{ GROUP } & \multirow[b]{2}{*}{$\mathbf{N}$} & \multicolumn{2}{|c|}{ PRE } & \multicolumn{2}{|c|}{ MID } & \multicolumn{2}{|c|}{ POST } & \multirow[b]{2}{*}{$\mathbf{F}$} & \multirow[b]{2}{*}{$p^{*}$} & \multirow[b]{2}{*}{$\eta^{2}$} \\
\hline & & & M & SD & $\mathbf{M}$ & SD & $\mathbf{M}$ & SD & & & \\
\hline \multirow{3}{*}{$\begin{array}{l}\text { Attitudes: } \\
\text { Searching } \\
\text { intentions }\end{array}$} & Interv. & 48 & 3.59 & 0.60 & 3.64 & 0.62 & 3.39 & 0.69 & \multirow{2}{*}{.324} & \multirow{2}{*}{.724} & \multirow{2}{*}{.004} \\
\hline & Control & 31 & 3.60 & 0.61 & 3.54 & 0.69 & 3.31 & 0.59 & & & \\
\hline & Total & 79 & 3.59 & 0.60 & 3.60 & 0.64 & 3.36 & 0.65 & 8.532 & $.000^{1}$ & .100 \\
\hline \multirow{3}{*}{$\begin{array}{l}\text { Attitudes: } \\
\text { Evaluation } \\
\text { intentions }\end{array}$} & Interv. & 48 & 3.29 & 0.72 & 3.40 & 0.73 & 3.42 & 0.74 & \multirow{2}{*}{4.050} & \multirow{2}{*}{$.019^{2}$} & \multirow{2}{*}{.050} \\
\hline & Control & 31 & 3.44 & 0.73 & 3.21 & 0.80 & 3.13 & 0.63 & & & \\
\hline & Total & 79 & 3.35 & 0.72 & 3.32 & 0.76 & 3.31 & 0.71 & .656 & .521 & .008 \\
\hline \multirow{3}{*}{$\begin{array}{l}\text { Attitudes: } \\
\text { Writing } \\
\text { intentions }\end{array}$} & Interv. & 47 & 3.61 & 0.91 & 3.79 & 0.77 & 3.81 & 0.75 & \multirow{2}{*}{3.533} & \multirow{2}{*}{$.032^{3}$} & \multirow{2}{*}{.044} \\
\hline & Control & 31 & 3.74 & 0.63 & 3.51 & 0.83 & 3.70 & 0.57 & & & \\
\hline & Total & & 3.66 & 0.81 & 3.68 & 0.80 & 3.77 & 0.68 & 1.028 & .360 & .013 \\
\hline \multirow{3}{*}{$\begin{array}{l}\text { Attitides: } \\
\text { Online } \\
\text { learning }\end{array}$} & Interv. & 50 & 3.67 & 0.55 & - & - & 3.55 & 0.70 & \multirow{2}{*}{.198} & \multirow{2}{*}{.657} & \multirow{2}{*}{.002} \\
\hline & Control & 32 & 3.87 & 0.79 & - & - & 3.82 & 0.59 & & & \\
\hline & Total & 82 & 3.74 & 0.66 & - & - & 3.65 & 0.67 & 1.033 & .313 & .013 \\
\hline \multirow{3}{*}{$\begin{array}{l}\text { Attitudes: } \\
\text { Traditional } \\
\text { learning }\end{array}$} & Interv. & 50 & 3.41 & 0.74 & - & - & 3.17 & 0.81 & \multirow{2}{*}{.009} & \multirow{2}{*}{.926} & \multirow{2}{*}{.000} \\
\hline & Control & 32 & 3.67 & 0.71 & - & - & 3.41 & 0.55 & & & \\
\hline & Total & 82 & 3.51 & 0.74 & - & - & 3.26 & 0.73 & 10.308 & $.002^{4}$ & .114 \\
\hline \multirow{3}{*}{$\begin{array}{l}\text { Self- } \\
\text { efficacy: } \\
\text { Searching }\end{array}$} & Interv. & 48 & 4.08 & 0.52 & 4.11 & 0.49 & 4.12 & 0.55 & \multirow{2}{*}{.510} & \multirow{2}{*}{.602} & \\
\hline & Control & 31 & 4.10 & 0.52 & 4.12 & 0.54 & 4.24 & 0.39 & & & .007 \\
\hline & Total & 79 & 4.09 & 0.52 & 4.12 & 0.51 & 4.16 & 0.49 & .997 & .371 & .013 \\
\hline Self- & Interv. & 48 & 4.20 & 0.63 & 4.09 & 0.56 & 4.08 & 0.61 & 586 & 550 & $0 \Omega e$ \\
\hline efficacy: & Control & 31 & 4.15 & 0.48 & 4.14 & 0.60 & 4.16 & 0.43 & .586 & .558 & .008 \\
\hline Writing & Total & 79 & 4.18 & 0.57 & 4.11 & 0.57 & 4.11 & 0.54 & .566 & .569 & .007 \\
\hline
\end{tabular}

* statistically significant $\mathrm{p}<0.05$

1) $\operatorname{pre}>\operatorname{post}\left(\mathrm{p}=.000, \eta^{2}=.184\right)$, mid $>\operatorname{post}\left(\mathrm{p}=.002, \eta^{2}=.123\right)$

2) $\operatorname{pre}<$ post $\left(p=.004, \eta^{2}=.103\right)$, mid $<$ post $\left(p=.048, \eta^{2}=.050\right)$

3) $\operatorname{pre}<\operatorname{mid}\left(\mathrm{p}=.021, \eta^{2}=.069\right)$

4) pre $>$ post

The results also indicate that the intervention had an effect on the students' 
behavioural intentions in writing $\left(\mathrm{F}(2,152)=3.533, \mathrm{p}=.032\right.$, partial $\left.\eta^{2}=.044\right)$. The effect size was again nearly medium. Within-subjects contrasts showed that there was a statistically significant difference between pre- and mid-measurements $(\mathrm{p}=.021$, partial $\left.\eta^{2}=.069\right)$. No difference was observed between the pre- and post-measurements $(\mathrm{p}=.085)$, or mid- and post-measurements $(\mathrm{p}=.270)$. Figure 1 shows the change in the test scores over time in the intervention and control group regarding behavioural intentions in evaluation and writing.

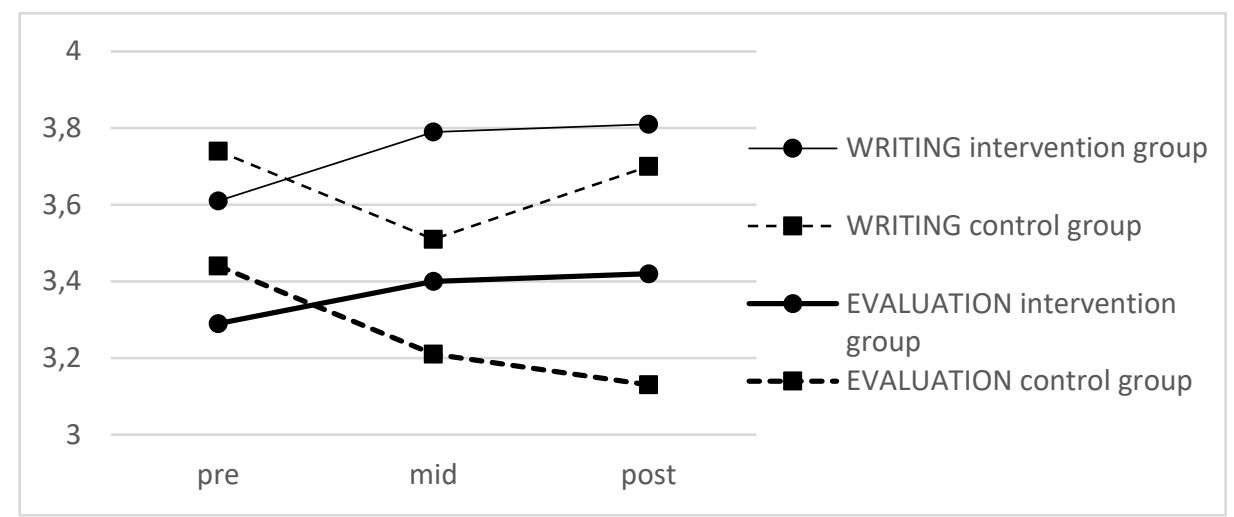

Figure 1. The effects of the intervention on students' behavioural intentions in evaluation and writing.

No statistically significant difference was found between the intervention and control group regarding the development of students' searching intentions $(F(2,154)=$ $.324, \mathrm{p}=.724)$. The intervention had no effect on the affective and cognitive attitudes measured by the factors online learning $(\mathrm{F}(2,80)=.198, \mathrm{p}=.657)$ and traditional learning $(\mathrm{F}(1,80)=.009, \mathrm{p}=.926)$. The teaching intervention had no effect on students' self-efficacy beliefs in searching for information $(\mathrm{F}(2,154)=.510, \mathrm{p}=.602)$ or in writing $(\mathrm{F}(2,154)=.586, \mathrm{p}=.558)$.

\section{Discussion}

The aim of this study was to investigate the effect of long-term, inquiry-based, curriculum-embedded information literacy instruction on students' self-efficacy beliefs and attitudes. The results show that the teaching intervention had a positive effect on students' behavioural intentions regarding the evaluation of search results and writing. No effect was observed in other attitude factors or self-efficacy beliefs.

The students in the intervention group adopted more developed behavioural intentions in the evaluation of search results. Most of the development happened during the first year. It can be explained by the fact that the first two courses explicitly required the students to practice evaluation. Source criticism was emphasized, especially in the second course. Learning to evaluate the trustworthiness of sources was set as an 
important learning goal by the history teachers. [20.] The last course was more focused on finding arguments for a speech.

The results also suggest that the intervention group adopted more advanced intentions in source-based writing. Again, the change took place during the first year and can be explained by the type of assignments. In the first two courses, students wrote a lot, but not in the last one where the end product was a speech. Especially the second course required a lot of writing in two subjects. Also the teachers reported that the students made progress in writing. [20.]

One of the learning goals of the intervention was to learn to search on the Web and other information channels. However, no difference was found between the groups regarding the development of students' behavioural intentions in searching. This unfortunate result requires further consideration: during the whole research period, the teachers for the intervention group reported that the students had problems in searching for information. The short instruction that the school librarian offered in the beginning of the seventh grade was obviously not enough. The teachers did not design any concrete activities to practice Web searching. For example, the importance of finding a personal viewpoint on the topic was emphasized but not demonstrated regarding how to apply these ideas in searching. After the third course, the teacher argued that she should have emphasized searching practices more. [20.]

The results suggested that the teaching intervention had no effect on students' selfefficacy beliefs because no change took place in self-efficacy scores either in the intervention or in the control group. However, this result is difficult to interpret alone because the development of skills and self-efficacy beliefs might interact. As Bellini et al. [25] and Aesaert et al. [6] argued, the self-efficacy beliefs of inexperienced individuals are typically inaccurate and unrealistically high, and when they get more experienced, their self-evaluations become more accurate and less biased. This means that if students' skills are improved in the intervention (students get more experienced), their estimates of self-efficacy will become more accurate. Yet, the scores of selfefficacy belief might go up, remain the same, or go down. All depends on what was the original level of their beliefs and how much their skills developed in the intervention. Our preliminary results of students' performance tests show that skills improved in the intervention group [26, forthcoming]. Thus, we may make a paradoxical conclusion that the intervention might have an effect on students' self-efficacy belief although they remained at the same level. This will be further elaborated on in the forthcoming paper.

Unlike in the research of Koksal and Berberoglu [13] and Gibson and Chase [12], our results suggest that the intervention did not affect students' attitudes, except behavioural intentions in evaluation and writing. Similarly to our findings, the intervention in Pinto and Fernandez-Pascual [11] did not lead to substantial progress in university students' attitudes.

The two-year period from the seventh grade to the eighth grade is an exceptionally long time to collect data about the effects of a teaching intervention. Other factors external to the intervention may affect the development of students' attitudes. We found two examples of this type of change in our data. Firstly, in the whole sample (intervention and control group together), the scores changed to favour less traditional forms of teaching and learning $\left(\mathrm{F}(1,80)=10.308, \mathrm{p}=.002\right.$, partial $\left.\eta^{2}=.114\right)$. This 
trend was not connected to the intervention, nor to any change in the attitudes to online learning, suggesting that some other factors external to the study might be behind this trend. Secondly, the analysis revealed that the scores across the groups in behavioural intentions in searching $\left(\mathrm{F}(2,154)=8.532, \mathrm{p}=.000\right.$, partial $\left.\eta^{2}=.100\right)$ showed a declining trend. This means that the students as eighth graders were less likely to follow good searching practices presented in the questionnaire items.

\section{Conclusions}

This study generated new knowledge about information literacy instruction and its effect on students beyond procedural knowledge and skills. Results revealed that the teaching intervention changed students' attitudes positively in terms of behavioural intention in the evaluation of search results and source-based writing, but no effect was observed in other factors.

The results demonstrate the importance of the type of the activities and especially the training that they offer to the students. When students were more engaged in certain aspects of IL and online research, their behavioural intentions regarding these aspects improved. In other words, through training, students become aware of good practices and hopefully will use them in real life, as well. However, the results imply that in lower secondary school, students seems to need continuous training in order to acquire and maintain good information literacy and online research practices.

All in all, it seems to be a challenge to develop self-efficacy beliefs or attitudes through IL instruction. They should be considered as explicit learning goals and explicit attention should be given to them.

The case study focused on students at one single school. Subsequently, the results cannot be generalized to Finnish lower secondary schools or other schools.

Acknowledgements. The study was funded by the Faculty of Communication Sciences at the University of Tampere, Finland. We thank the students and teachers participating in the study. We also thank our colleagues at the TRIM research center for their constructive comments on the manuscript.

\section{References}

1. Association of College and Research Libraries (ACRL): Information Literacy Competency Standards for Higher Education. American Library Association, Chicago (2000).

2. Oakleaf, M.: Using Rubrics to Assess Information Literacy: an Examination of Methodology and Interrater Reliability. Journal of the American Society for Information Science and Technology, 60(5), 969-983. (2009)

3. Pinto, M., Fernández-Pascual, R.: How a cycle of information literacy assessment and instruction stimulates attitudes and motivations of LIS students: A competency-based case study. Journal of Librarianship and Information Science, 0961000617742447. (2017)

4. Bandura, A.: Self-efficacy: toward a unifying theory of behavioral change. Psychological 
review, 84(2), 191-215. (1977)

5. Kurbanoglu, S. S.: Self-efficacy: a concept closely linked to information literacy and lifelong learning. Journal of Documentation, 59(6), 635-646. (2003)

6. Aesaert, K., Voogt, J., Kuiper, E., van Braak, J.: Accuracy and bias of ICT self-efficacy: An empirical study into students' over-and underestimation of their ICT competences. Computers in Human Behavior, 75, 92-102. (2017)

7. Bandura, A.: Perceived self-efficacy in cognitive development and functioning. Educational psychologist, 28(2), 117-148. (1993)

8. Bandura, A.: Social cognitive theory of self-regulation. Organizational behavior and human decision processes, 50(2), 248-287. (1991)

9. Eagly, A. H., Chaiken, S.: The psychology of attitudes. Harcourt Brace Jovanovich College Publishers, Orlando (1993)

10. Joyce, M., Kirakowski, J.: Measuring Attitudes Towards the Internet: The General Internet Attitude Scale. International Journal of Human-Computer Interaction, 31(8), 506-517. (2015)

11. Pinto, M., Pascual, R. F.: Exploring LIS students' beliefs in importance and self-efficacy of core information literacy competencies. College \& Research Libraries, 77(6). (2016)

12. Gibson, H. L., Chase, C.: Longitudinal impact of an inquiry - based science program on middle school students' attitudes toward science. Science education, 86(5), 693-705. (2002)

13. Koksal, E. A., Berberoglu, G.: The effect of guided-inquiry instruction on 6th grade Turkish students' achievement, science process skills, and attitudes toward science. International Journal of Science Education, 36(1), 66-78. (2014)

14. Conradi, K., Jang, B. G., Bryant, C., Craft, A., McKenna, M. C.: Measuring adolescents' attitudes toward reading: A classroom survey. Journal of Adolescent \& Adult Literacy, 56(7), 565-576. (2013)

15. Peng, H., Tsai, C. C., Wu, Y. T.: University students' self-efficacy and their attitudes toward the Internet: the role of students' perceptions of the Internet. Educational studies, 32(1), 7386 (2006).

16. Savolainen, R.: Information behavior and information practice: Reviewing the "umbrella concepts" of information-seeking studies. The Library Quarterly, 77(2), 109-132. (2007)

17. Bryman, A.: Social Research Methods (3rd ed.). Oxford University Press, Oxford (2008)

18. Price, P. C., Jhangiani, R.S., Chiang, I-C. A.: Research Methods in Psychology (2nd ed.) https://opentextbc.ca/researchmethods/ (2015)

19. Kuhlthau, C. C., Maniotes, L. K., Caspari, A. K.: Guided Inquiry. Learning in the 21 st Century (2nd ed.). Libraries Unlimited, Santa Barbara (2015)

20. Alamettälä, T., Sormunen, E.: Lower Secondary School Teachers' Experiences of Developing Inquiry-Based Approaches in Information Literacy Instruction. In European Conference on Information Literacy (ECIL 2017), pp. 683-692. Springer, Cham (2018)

21. Putman, S. M.: Exploring Dispositions Toward Online Reading: Analyzing the Survey of Online Reading Attitudes and Behaviors. Reading Psychology, 35(1), 1-31. (2014)

22. Field, A.: Discovering statistics using IBM SPSS statistics. Sage, London (2013)

23. Karras, D. J.: Statistical methodology: II. Reliability and validity assessment in study design, part A. Academic Emergency Medicine, 4(1), 64-71. (1997)

24. Pallant, J.: SPSS Survival Manual. A step by step guide to data analysis using IBM SPSS (5th ed.). Open University Press, Maidenhead (2013)

25. Bellini, C. G. P., Isoni Filho, M. M., de Moura Junior, P. J., de Faria Pereira, R. D. C.: Selfefficacy and anxiety of digital natives in face of compulsory computer-mediated tasks: A study about digital capabilities and limitations. Computers in Human Behavior, 59, 49-57. (2016)

26. Alamettälä, T., Sormunen, E.: The effect of a long-term teaching intervention on students' online research skills in lower secondary education. (forthcoming) 